POLIGRAFÍAS. REVISTA DE TEORÍA LITERARIA Y LITERATURA COMPARADA. NÚMERO 1. NUEVA ÉPOCA.

() UNAM TODOS LOS DERECHOS RESERVADOS

https://doi.org/10.22201/ffyl.poligrafiasnuevaepoca.2011.1.1656

\title{
La teoría elizondiana del antitiempo en Farabeuf o el tiempo visto desde el espejo
}

LUIS ANDRÉS GUTIÉRREZ VILLAVICENCIO

Facultad de Filosofía y Letras, UNAM

Un río jamás puede regresar a sus fuentes.

Ts'ai Yen

¿Quién ha decretado que un torrente debe fluir de arriba hacia abajo?

Lo que el hombre llama leyes de la naturaleza no son más que unas generalizaciones de los fenómenos que él mismo no alcanza a comprender.

Masami Kurumada

El problema central de la metafísica está en la comprensión del tiempo. La mayoría de los físicos y filósofos proponen, más que un concepto sustancial, una noción empírica. La más cercana al sentido común, y también la más práctica para realizar cálculos, es la idea aristotélica de que el tiempo es la medida del movimiento según el antes y el después. Hobbes con su idea de sucesión, Newton con la de acción y reacción, y Kant con su principio de causalidad, son avatares de la misma idea. El encadenamiento de causas y consecuencias hace posible el logos, porque le confiere un orden al cosmos. No existe el azar, sólo el desconocimiento de todas las variables implicadas en una situación. Para Laplace, las ideas de acción y reacción newtonianas lo llevan a afirmar que llegará el día en que con una sola fórmula se podrá predecir el futuro, pues en ella podrán computarse todas las variables de un fenómeno.

La ciencia occidental está basada en el principio de causalidad, que a su vez depende de la dirección en la cual se manifiesta el mundo sensible. Los científicos llaman a esto la flecha del tiempo.

Hay al menos tres flechas del tiempo diferentes. Primeramente, está la flecha termodinámica, que es la dirección del tiempo en la que el desorden o la entropía aumentan. Luego está la flecha psicológica. Ésta es la dirección en la que nosotros sentimos que pasa el tiempo, la dirección en la 
que recordamos el pasado y no el futuro. Finalmente, está la flecha cosmológica. Esta es la dirección del tiempo en la que el universo está expandiéndose en vez de contrayéndose (Hawking, 1988: 191).

La más importante de estas tres es la flecha termodinámica, porque determina la dirección de todos los procesos del universo, desde un estado ordenado, a uno de mayor desorden. Según esta ley todo tiende al desgaste, al agotamiento y a la degradación. Ésta es la esencia fatal e ineluctable del universo: todo muere y se consuma y se consume por el tiempo.

La flecha psicológica es consecuencia de la entropía: la forma en que el hombre percibe el mundo fenoménico. El recuerdo discurre hacia lo ya hecho, pero nunca hacia lo que será. Esta idea es válida en un esquema de tiempo lineal y progresivo, pero no así en uno que se base en el tiempo cíclico, pues en éste ya todo ha acontecido y se ha repetido infinitamente a lo largo de los siglos, y si se conoce el ciclo primigenio del cosmos, es posible, también, recordar el porvenir. En su cuento "El informe de Brodie", Borges le confiere a una tribu de "salvajes" este curioso don:

Gozan también de la facultad de la previsión; declaran con tranquila certidumbre lo que sucederá dentro de diez o quince minutos. [...] Sabemos que el pasado, el presente y el porvenir ya están, minucia por minucia, en la profética memoria de Dios, en su Eternidad; lo extraño es que el hombre pueda mirar, indefinidamente, hacia atrás pero no hacia delante. [...] Filosóficamente, la memoria no es menos prodigiosa que la adivinación del futuro; el día de mañana está más cerca de nosotros que la travesía del Mar Rojo por los hebreos, que, sin embargo, recordamos (Borges, 1970: 451-452).

En el tiempo cíclico no hay desgaste, porque cada periodo termina al comienzo de sí mismo; es la serpiente que se muerde la cola y la lemniscata que nunca termina.

La entropía también puede anularse en un universo aún más difícil de concebir, pero igualmente fascinante: uno cuya causalidad fluya a la inversa. Elizondo explica que esto no es imposible y que la ciencia ha logrado incluso algunos avances en este campo:

Los científicos han conseguido regresar el curso de ciertos procesos atómicos a estados anteriores artificialmente, por ejemplo. Elementos cuyo transcurrir consiste en transformarse en otros elementos (es el caso de los elementos radioactivos) han sido convertidos en elementos que en el curso de esa actividad son anteriores a ellos mismos (Elizondo, 1994b: 399). 
La dirección del tiempo es, como asegura Einstein, una cuestión meramente probabilística, si bien se trata de una ilusión muy persistente. A pesar de los esfuerzos que se realicen nunca se podrá invertir la flecha de la entropía, cuando menos no en este universo. Una entropía decreciente es posible, dice Elizondo, pero implica la existencia de otro universo paralelo al nuestro. En su ensayo "Del tiempo y del río" expone su creencia en un antitiempo:

No es la menos interesante de todas las teorías sobre el tiempo una que deriva de una teoría de la naturaleza que es, muy particularmente, un domino en el que destacan los científicos chinos. La doctrina de un anti-universo, es decir, de un universo de signo contrario al que conocemos, es una de las teorías más viables para explicar ciertos fenómenos que se producen en el campo de la física nuclear, pero a partir de los cuales no es difícil concebir una teoría general del universo concebido como equilibrio de fuerzas antagónicas. La antimateria es un trabajo tan eficaz que permite explicar muchos procesos de la transformación de la materia. Pareja a la concepción de esta antimateria tiene que haber una concepción del anti-tiempo. $\mathrm{Y}$ en efecto existe. Los matemáticos, para explicar algunos procesos no pueden menos que invocar un universo al que se le ha dado el nombre de universo "fáustico" en el que el tiempo pasa al revés que en el nuestro, y en el que todas las mismas cosas que en nuestro universo conocido o concebido se dirigen hacia su destino final, allí se dirigen hacia sus orígenes, como en el poema de Gorostiza (Elizondo, 1994b: 400).

La regresión del tiempo es uno de los temas predilectos de Elizondo. En diversos ensayos y cuentos experimenta las alternativas que ofrece esta posibilidad. En "Futuro imperfecto", el personaje Elizondo se topa con el crítico literario Soamez, quien le dice que en el futuro escribirá un artículo basado en el encuentro con él. Ante la refutación de Elizondo, que dice que no escribirá tal ensayo, Soamez replica que para rehuir su destino "precisaría que el curso del tiempo fluyera al revés para que todo lo que en estas líneas está escrito se des[es]cribiera" (Elizondo, 1994b: 191); en "Anapoyesis", un científico construye una máquina: "El anapoyetron es como una cámara cinematográfica que funciona de adelante hacia atrás" (Elizondo, 1994c: 34); en "La luz que regresa", Elizondo pone en boca del doctor Moriarty las ideas de J.W. Dunne acerca del tiempo, y las convierte en elemento de su prosa: “El tiempo es un sistema de cintas que corren en diversas direcciones y diferentes velocidades [...] es posible mediante mi invento pasar de una a otra, aumentar o disminuir su velocidad, detener su marcha, regresar su curso" (Elizondo, 1994c: 133). 
Farabeuf es un texto cuyas características atentan contra las nociones básicas de una novela, que requiere de movimiento, de acción y devenir para ser. Farabeuf es la crónica de un instante que no acaba nunca de transcurrir, porque está encerrado en sí mismo, porque se recuenta una y otra vez, porque es uno y es muchos, pero también porque es tiempo que fluye inversamente.

Hay dos métodos que emplea Elizondo para invertir el tiempo en Farabeuf: uno de ellos está en la forma (la retrospección) y uno más en el contenido (la narración regresiva).

\section{La retrospección ${ }^{1}$}

El centro del universo de Farabeuf está en París. Desde ahí se narra y se recuerda el resto de la historia. La anécdota nodal de lo ocurrido en Odeon se puede resumir así: una mujer mira la foto de un suplicio chino y desea, excitada, sentir el clímax de un coito sangriento en su cuerpo. Llama por teléfono al doctor Farabeuf y lo invita a su casa. Durante la espera, consulta el I ching/ la ouija, se levanta y choca contra una mesa de metal y traza, nostálgica, un signo en la ventana. El doctor traspone el umbral de la entrada y se coloca junto a ella, frente al espejo. Después ambos se dirigen a un cuarto en el cual no se sabe qué ocurre. Sólo se escucha un grito de dolor o de placer que marca un clímax ambiguo, tras el cual, el doctor recoge su instrumental y sale de esa casa para no volver jamás.

En la novela estos acontecimientos nunca son contados tan ordenadamente. Elizondo prefiere narrar del modo opuesto. El más sencillo de sus procedimientos es la retrospección ordenada. Para lograrla, divide su historia en escenas, relata la última, y al término de ésta, la penúltima, y así hasta contar la primera. La enumeración del instrumental del cirujano es un indicio de este modo de narrar:

Repase usted en su mente la lista del instrumental. Para ello puede usted emplear diversos métodos. Puede usted, por ejemplo, repasar cada uno de los instrumentos en orden descendente de tamaños [...]. Puede usted cerciorarse, también, aplicando este método inversamente, por orden ascendente de tamaños. Es preciso, sobre todo, que no deje usted nada olvidado aquí (Elizondo, 1994a: 8).

\footnotetext{
${ }^{1}$ Este término lo emplea también Harald Weinreich. Genette prefiere llamarlo analepsis o exposición retardada.
} 
El empleo de uno u otro método es irrelevante. La eficacia de ambos es exactamente la misma, como sucede con la propiedad conmutativa de la multiplicación, en la cual el orden de los factores no altera el producto. Uno de los narradores de la antinovela de Elizondo pone en marcha el mismo juego del instrumental, pero lo aplica al tiempo.

El segundo párrafo de la primera parte refiere el final de la anécdota: “¿Está usted seguro de no haber olvidado nada? Cualquier indicio de su presencia en esta casa puede tener consecuencias terribles e irremediables"; el siguiente párrafo se centra en la llegada del doctor: “Es un anciano - el hombre - que llega a pie desde el Carrefour, enfundado en un grueso abrigo de paño negro"; y más abajo concluye con la acción que justifica su presencia en ese lugar: "Has venido porque ella - la mujer - te ha llamado hace apenas media hora".

La retrospección ordenada de Farabeuf es una concreción literaria de aquello que Borges propone en su cuento "Examen de la obra de Herbert Quain":

Aún más heterodoxa es la "novela regresiva, ramificada" April March. [...] Hasta el nombre es un débil calembour: no significa marcha de Abril sino literalmente Abril marzo. Alguien ha percibido en sus páginas un eco de las doctrinas de Dunne; el prólogo de Quain prefiere evocar aquel inverso mundo de Bradley, en que la muerte precede al nacimiento y la cicatriz a la herida y la herida al golpe. [...] Los mundos que propone April March no son regresivos; lo es la manera de historiarlos. Regresiva y ramificada, como ya dije. Trece capítulos integran la obra. El primero refiere el ambiguo diálogo de unos desconocidos en un andén. El segundo refiere los sucesos de la víspera del primero (Borges, 1944: 462).

La regresión cronológica ordenada tanto de April March como de Farabeuf no es gratuita. Ambos implican un ejercicio de inversión de pensamiento en el lector, el cual consiste en darle a conocer un hecho y obligarlo a intuir sus posibles causas. El significado de una acción se multifurca infinitamente hacia el pasado, lo cual enriquece la recepción del texto. Se cuenta que el doctor recoge su instrumental y las descripciones del mismo obligan a imaginar el uso que se le ha dado; su llegada a la casa no resuelve la intriga, sino que abre nuevas preguntas y posibilidades.

Giovanni Papini argumenta que este procedimiento es idóneo para comprender la naturaleza de cualquier acto. En su texto "La Historia al revés" denigra a aquellos que explican todo aristotélicamente: 
Su error, como el de todos los historiadores del mundo, procede de la encallecida imbecilidad, ahora milenaria, que hace comenzar toda historia por un hipotético principio hasta llegar hasta un fin próximo a nosotros. [...] No destruyo la cronología si en vez de comenzar por el uno para llegar al mil, me apoyo en el mil para remontarme hasta el uno. [...] Mi método, que consiste en retroceder desde el presente hacia el pasado, es el más lógico, el más natural, el más satisfactorio. [...] Para comprender a un gran hombre es preciso referirse, necesariamente, al día de su muerte. La vida de César comienza efectivamente el día en que fue asesinado. ¿Por qué fue asesinado? De aquí podemos dirigirnos directamente a sus ambiciones, a sus campañas, a su dictadura (Papini, 1931: 29).

El después es lo que explica el antes, y no viceversa. Referir el final e ir hacia sus causas descubre el alcance incalculable de un acontecimiento: el interés del lector aumenta si primero se hace alusión a las terribles consecuencias, al resultado de algo que se desconoce, pero cuya naturaleza se intuye atroz.

\title{
La narración regresiva
}

\author{
Marcial tuvo la sensación extraña \\ de que los relojes de la casa daban las cinco, \\ luego las cuatro y media, luego las cuatro, \\ luego las tres y media... \\ Era como la percepción remota de otras posibilidades.
}

Alejo Carpentier

Historiar al revés no modifica la naturaleza del tiempo, sino la temporalidad, es decir, la percepción subjetiva que el lector tiene del mismo. Aunque se narre del final al principio, como ocurre con la retrospección ordenada, el universo sigue las leyes newtonianas del antes y el después. Revertir verdaderamente el tiempo es invertir la causalidad del acto. En ese mundo intuido por Bradley, en el cual la muerte precede a la herida y la herida al puñal, el efecto se vuelve causa y la causa consecuencia. Dunne explica que ese invisible universo puede existir, fluyendo calladamente en un cauce paralelo al nuestro. Stephen Hawking confiesa que alguna vez también vislumbró esa posibilidad, y explica así cuáles serían sus características principales:

En los primeros momentos, el universo habría estado desordenado. Esto significaría que el desorden disminuiría con el tiempo. Usted vería vasos rotos recomponiéndose ellos solos y saltando hacia la mesa. Sin embargo, ningún ser humano que estuviese observando los vasos 
estaría viviendo en un universo en el cual el desorden disminuyese con el tiempo. Razonaré que tales seres tendrían una flecha psicológica del tiempo que estaría apuntando hacia atrás. Esto es, recordarían sucesos en el futuro y no recordarían sucesos en el pasado. Cuando el vaso estuviese roto lo recordarían recompuesto sobre la mesa, pero cuando estuviese recompuesto no lo recordarían estando en el suelo (Hawking, 1988: 193).

La ciencia en ese universo no podría desarrollarse con los mismos presupuestos occidentales, pues todas las fórmulas de esta cultura dependen del conocimiento de las causas, y ahí éstas serían posteriores. La ciencia oriental, en cambio, prevalecería, porque se basa en el principio de sincronicidad, que es la homología de dos fenómenos en un mismo instante. Los sistemas de adivinación, por ejemplo, se basan en la creencia de que el universo está en completa sincronía en un momento dado, por lo tanto, basta con entender cuál es el estado actual de los astros, o la disposición de las vísceras de un animal, para homologarlo con el del hombre. Acupuntura, moxibustión, Wushu, Tai ji y demás disciplinas orientales están basadas en la sincronización de los seres en el espacio; en cambio en Occidente, (leyes físicas, biológicas y fisiológicas) se basan en el cambio de los seres en el tiempo.

La lógica de estos fenómenos antientrópicos modificaría también la "finalidad" de cada acción, pues todo sería una búsqueda de regreso al origen, una suerte de descreación del universo. En su texto "La fundación de Roma", Elizondo conjetura algunas de las propiedades paradojales de ese fluir temporal:

Sería como realizar el acto amoroso al revés. En ese universo las pasiones serían una urgencia de quietud, una aspiración irrefrenable de dolor, una abominación del placer. El artista sería aquél que fuera construyendo lo increado, descreando lentamente la obra de arte. Todo nacer sería una disminución del universo y la muerte el comienzo de un viaje, el universo la Nada y el efecto siempre anterior a la causa. [...] Todo iría perdiéndose en sus orígenes. Un mundo en el que todas las cosas irían hacia el momento que las antecede en el orden de la existencia. La nostalgia sería la premonición de un gesto y el ensueño, la forma suprema del recuerdo. [...] El ideal inherente a la raza humana sería la Regresión (Elizondo, 1994b: 57-59).

En "Viaje a la semilla", Carpentier explora literariamente la extraña lógica de este universo fáustico. Al comienzo del relato, un hombre viejo, don Marcial, muere, y un chamán, al voltear su cayado, invierte también el flujo del tiempo, y entonces todo lo que había sido destruido por el peso de los años vuelve a levantarse. Don Marcial va de la muerte a su 
juventud, de su adolescencia a la niñez, y al final regresa al vientre de su madre y deja de ser. Esa reversión de los procesos entrópicos es también un ejercicio de extrañamiento, porque todo lo que se percibe, al mirarse 'al revés', se convierte en algo completamente nuevo, es como observar el mundo por primera vez, pero a diferencia de aquél que conocemos, el universo invertido de Carpentier es optimista, cada escena va desatando los nudos del tiempo, del compromiso humano y de las cadenas que son el desgaste.

La Marquesa trocó su vestido de viaje por un traje de novia, y, como era costumbre, los esposos fueron a la iglesia para recobrar su libertad. Se devolvieron presentes a parientes y amigos, $\mathrm{y}$, con revuelo de bronces y alardes de jaeces, cada cual tomó la calle de su morada. Marcial siguió visitando a María de las Mercedes por algún tiempo, hasta el día en que los anillos fueron llevados al taller del orfebre para ser desgrabados (Carpentier, 1944: 61).

El regressus ad uterum de "Viaje a la semilla" es posible gracias a un acto de magia: la inversión del cayado del chamán. Elizondo, escritor más visual, prefiere otro método: el espejo, que finge poseer un espacio del cual carece. Dar la cara a un espejo es enfrentarse con un universo invertido, en el cual se confunden la derecha y la izquierda y a veces también lo real y lo virtual, el otro y el yo. Para Elizondo, sobre esta superficie se transmuta toda la realidad: “El espejo es el instante en el que el curso del tiempo se trastrueca y el pasado se vuelve porvenir" (Elizondo, 1994b: 57-59).

Un indicio de la regresión temporal está al principio de la segunda parte: “Al llegar al umbral de aquella puerta reflejada en el espejo. Algo, quizá una mirada cruel me contuvo y me hizo volverme hacia aquel camino que acababa de andar" (Elizondo, 1994a: 32). El doctor, a punto de entrar, se detiene al mirar el espejo y regresa por el camino andado. Otro de los momentos indiciales es la propuesta de contar del uno al cien o viceversa, lo cual rompe con la jerarquía del atrás y adelante, del menos al más y la del antes y el después: “Cuando yo te diga, empezarás a contar, uno, dos, tres, o si prefieres, puedes también hacerlo en orden descendente a partir de cien: cien, noventa y nueve, noventa y ocho y así sucesivamente, sin apresurarte..." (Elizondo, 1994a: 36).

El momento en el cual se invierte verdaderamente el flujo del tiempo es cuando uno de los dos personajes 'sale' del espejo: 
Has caminado ya; saliendo del espejo has cruzado este salón oliente aún a los desinfectantes que él dejó olvidados sobre el turbio mármol de la mesilla. Has caminado lentamente hacia el pequeño armario que está junto al tocadiscos sin mirarme al pasar frente a mí. Has abierto uno de los cajoncillos y has sacado una vieja fotografía, manchada por la luz del tiempo. Mientras tanto él se preparaba para salir $y$, dejando olvidados ciertos instrumentos sobre la mesilla, guardaba cuidadosamente los demás en el viejo maletín de cuero negro. Largo rato te has quedado mirando ensimismada aquel rostro difuso grabado en la fotografía. Luego te dirigiste al teléfono (Elizondo, 1994a: 36).

En este antitiempo, las escenas se ven como en el rebobinado de una película. Todo comienza en un estado de completo desorden (el salón oliente a desinfectante), y concluye ordenadamente (Ella llamando al doctor por teléfono). La causalidad invertida produce una dificultad en la comprensión de lo que ocurre en ese lugar. No queda claro, por ejemplo, cómo es que Él esté a punto de salir y un rato después Ella lo llame por teléfono. En este antiuniverso todo ocurre en reversa, desde su incierto fin hasta un principio en el cual todo parece ordenado.

La idea de la inversión temporal frente al espejo tiene su génesis en la convicción elizondiana de que el mundo es un texto que él mismo escribe: así, las páginas de ese libro, colocadas frente a esa superficie que conmuta izquierda y derecha y leídas según el mismo orden de las lenguas romances, presentan los actos al revés de como fueron escritos en un principio. Algo semejante ocurre en El hipogeo secreto, cuando dos de sus personajes encuentran un libro en el que se menciona su propia historia:

No es allí donde hay que leer, sino más adelante. Pasa unas cuantas páginas y léeme un poco... ¿Qué dices?.... una mujer recibe una carta, sí... que perteneces a una organización secreta que se llama el Urkreis. No; eso era antes. Pasa más páginas... ¿ ¿el dibujo?... ¡No, no!... Lo que pasa es que estás del otro lado del espejo y allí las páginas del libro se suceden en sentido inverso ¿entiendes? Es preciso que leas hacia el otro lado. (Alveolos transtemporantes...) (Elizondo, 1994a: 339).

En la segunda parte el espejo cobra capital importancia, porque se incluye como un narrador más de la obra: un narrador que cuenta todo desde una perspectiva irregular, en la cual todo está invertido, incluso el tiempo. Casi siempre es un nosotros que mira del futuro al pasado y que se percibe como consciencia actuante y cuyas conjeturas terminan por confundirse con las de los personajes del otro universo. 
Se acercaba poco a poco a donde nosotros estábamos y al mismo tiempo te miraba, absorta en aquella inquisición terrible (cien...), desde el fondo de aquel pasillo oscuro (noventa y nueve...), sin saber qué decir (noventa y ocho...) esperando tan sólo que la mano de Farabeuf (noventa y siete...) al tocar en la puerta (noventa y seis...) rompiera aquel encantamiento maligno (noventa y cinco...) en el que te anegabas como en un mar, ¿verdad? (noventa y tres...) (Elizondo, 1994a: 37).

El antiuniverso del espejo consta de una consciencia plural que no sólo percibe el mundo al revés, sino que también acumula el pasado y lo junta y revuelve dentro de sí. Es un museo, un depósito filmante de tiempo, como el cine. Sus límites espaciales dependen de su ubicación, y abarca la puerta de la entrada al salón, el pasillo en penumbras, un cuadro de Tiziano, una mesa de hierro, y acaso el quicio de una ventana. Con las imágenes que ha aprisionado en su memoria, ayuda a la mujer a recordar el paseo que dio con Él en la playa, hace ya varios años:

¿Y aquel espejo enorme? Hubo un momento en que reflejó su imagen. Se tomaron de la mano y durante una fracción de segundo fue como si estuvieran paseando a la orilla del mar, sin mirarse para no encontrar sus rostros, para no verse reflejados en esa misma superficie manchada y turbia que reflejaba también, imprecisa, mi silueta como un borrón blanquecino, inmóvil en el fondo de ese pasillo oscuro por el que Farabeuf habría de pasar apenas unos instantes después (Elizondo, 1994a: 40).

El espejo posibilita una serie interminable de superposiciones de estados en el tiempo y en el espacio, porque en él se mezclan varios acontecimientos. Cuando el doctor y la mujer se toman de la mano en París también lo hacen en la playa, en un antes que es también un ahora, gracias a la confluencia temporal del espejo, que mira, como la memoria, hacia el pasado; y de sus cuerpos, que están en el presente.

La proliferación de recuerdos pretéritos multiplica el número de personajes de la obra. En Odeon se encuentran la Enfermera, el doctor, Él, Ella, Farabeuf, Melanie, el hombre, la mujer, la monja, el cura, y un Nosotros que a veces abarca a todos y a veces a ninguno de todos ellos. Todos los tiempos confluyen en ese espejo enorme que se parece a la eternidad. Hay fragmentos de la obra en los que es notoria esta conjunción de tiempos y personajes que actúan simultáneamente: para la representación del cuadro de Tiziano que dirige uno de los narradores es necesario que dos mujeres de distintas series temporales se sincronicen al borde del espejo. Dentro de esa superficie ambas poseen consciencia de sí y de la otra: “Ahora ven; descansa un 
instante apoyada en este féretro. Posa tu mano derecha sobre el borde de modo que tu peso caiga sobre ella. [...] Quédate así un momento [...]. La Enfermera se colocará en una pose determinada de antemano, en el otro extremo del féretro" (Elizondo, 1994a: 145).

Farabeuf construye su semántica a partir de antagonismos complementarios: todos y cada uno de los elementos del texto se equiparan, se duplican y contraponen entre sí y a sí mismos una y otra vez: la mujer es la estrella de mar, el chino sufriente y el signo en la ventana, se opone a su torturador (el doctor) y a sí misma en su papel de Enfermera, se multiplica y opone igualmente en la que juega a la ouija, la que consulta al I ching, la que corre hacia la ventana y las que posan frente al espejo.

El salón tiene su doble en ese universo de dos dimensiones en el que ocurren acciones iguales, pero de signo opuesto. Ese mundo especular se opone a sí mismo porque refleja un espacio que le es ajeno (la playa). Ahí se confrontan también lo real y la apariencia, lo vivo y lo muerto; es el límite entre ser y no ser, es el espacio de la conjetura por la existencia. Todos los que ahí convergen dudan de su condición ontológica. “Estar representados significa estar ausentes ahí donde estamos siendo representados. Hay un tanto de suplantación de nosotros en nuestro representante y todo representante es el que ejerce la prerrogativa de que no le corresponde ónticamente" (Elizondo, 1994b: 222).

Lo reflejado en el espejo en Farabeuf es inquietante porque tiene consciencia de sí, y al igual que los seres de carne y hueso, las imágenes temen e intuyen ser simulacros. “¿Y si sólo fuéramos la imagen reflejada en un espejo?" (Elizondo, 1994a: 69). Lo reflejado no le pertenece al espejo, es mero préstamo, transitorio y fugaz. Los múltiples personajes de diversos tiempos que están encerrados ahí adentro observan lo que ocurre en el salón, y se preocupan por esa fugacidad, por esa posibilidad de dejar de existir en cualquier momento.

Su perspectiva es confusa, les impide saber quién es real, quién es sólo apariencia, porque todos poseen recuerdos, sensaciones, movimiento y deseos de existir:

- Deberá hacer usted, entre muchas otras, las siguientes preguntas:

1) Si es que somos tan sólo la imagen en un espejo, ¿cuál es la naturaleza exacta de los seres cuyo reflejo somos?

2) Si es que somos la imagen en un espejo ¿podemos cobrar vida matándonos? 
3) ¿Es posible procrear nuevos seres autónomos, independientes de los seres cuyo reflejo somos, si es que somos la imagen en un espejo, mediante la operación quirúrgica llamada acto carnal o coito? (Elizondo, 1994a: 75).

La insinuación metafísica de asesinar a los seres reflejados les añade intencionalidad y deseos de independencia. Con ello se anula la superioridad de lo real sobre el reflejo. Esa equiparación se cierra con los personajes del salón que se miran en el espejo y que tampoco están seguros de su condición; su identidad es fluctuante, todos están a punto de dejar de ser lo que son: "No importa ya para nada tu identidad real... Tal vez eres un hombre sin significado, un hombre inventado, un hombre que sólo existe como la configuración de otro hombre que no conocemos, el reflejo de un rostro en el espejo" (Elizondo, 1994a: 11). Las reflexiones de los personajes de ambos universos son tan similares que relativizan y resquebrajan la noción de Ser. ¿Quién es más real? ¿Los seres que están en el salón o los que pululan en el espejo? La única distinción es la lógica que los rige, pero una es tan válida como la otra.

Entre las dos logran su objetivo: hacer del texto un laberinto insalvable: porque si su tiempo fluye en ambos sentidos no hay manera de llegar al final. Farabeuf es película que se rebobina sin haber concluido; es postergación de lo inminente; es Penélope destejiendo su edredón; revisitación del pasado; y es, finalmente, recurrencia y palíndroma de tiempo, porque se puede leer del antes al después y en sentido opuesto.

El antitiempo de Farabeuf está en un universo inestable que oscila entre lo que es y lo que puede nunca haber sido. Lo constituyen apariencias que, sin embargo, adquieren por momentos más sustancia que los que habitan en ese otro mundo equívoco que se llama realidad. 
LUIS ANDRÉS GUTIÉRREZ VILLAVICENCIO. “EL ANTITIEMPO EN FARABEUF...”

\section{Bibliografía}

BORGES, Jorge Luis (2004): Obras completas I, 15ª edición, Buenos Aires: Emecé. ELIZONDO, Salvador (1994a): Obras: tomo uno, México: El Colegio Nacional. - (1994b): Obras: tomo dos, México: El Colegio Nacional.

- (1994c): Obras: tomo tres, México: El Colegio Nacional.

HAWKING, Stephen (1988): Historia del tiempo, 3a edición, México: Grijalbo.

PAPINI, Giovanni (2000): El libro negro/GOG, 4ª edición, México: Porrúa. 